Revista General de Información y Documentación ISSN: 1132-1873

http://dx.doi.org/10.5209/rgid.72820

\title{
Patrimonio documental, memorias e historia obrera. La reconstrucción del caso de Villa Carlos von Bernard, partido de Olavarría, Buenos Aires, Argentina
}

\author{
Griselda Lemiez ${ }^{1}$; María Luz Endere²
}

Recibido: 7 de julio de 2020 / Aceptado: 30 de julio de 2020

Resumen. En este trabajo abordamos la cuestión del patrimonio documental en relación a la reconstrucción de la historia de las empresas, tomando como caso de estudio la Villa Carlos von Bernard, en el partido de Olavarría, provincia de Buenos Aires, Argentina. Para ello analizamos el marco legal aplicable a este patrimonio y las dificultades que se presentan a la hora de proteger la documentación privada. Asimismo, indagamos acerca del valor social y cultural de los documentos, en sus diferentes soportes, como elementos del patrimonio cultural y su vinculación con la reconstrucción histórica, principalmente en la historia de las empresas. El caso abordado nos ilustra sobre cómo ante la falta de documentos de la fábrica, la reconstrucción histórica se hizo en base a fuentes alternativas, es decir periodísticas, judiciales, fotográficas, etc., apoyadas y/o contrastadas con la memoria oral de algunos de sus protagonistas. Finalmente deseamos recordar el rol que cumple el patrimonio documental en la memoria social y en las democracias, por lo que consideramos que debe preservarse y socializarse. Por esta razón resulta prioritario contar con un marco regulatorio adecuado y actualizado que lo ampare.

Palabras clave: Patrimonio documental; Archivos particulares; Legislación; Historia del trabajo.

[en] Documentary heritage, memories and working history. The reconstruction of the Villa Carlos von Bernard case, Olavarría District, Buenos Aires, Argentina

Abstract. In this paper the issue of documentary heritage in relation to the reconstruction of the history of companies is approached, taking as a case study the Villa Carlos von Bernard, in the Olavarría district, province of Buenos Aires, Argentina. In order to do this, we analyze the legal framework applicable to this heritage and the difficulties that arise when protecting private documentation. We also inquire about the social and cultural value of documents, in their different supports, as elements of cultural heritage and their link with historical reconstruction, mainly with the history of companies. The case demonstrates how, in the absence of documents of this factory, the

1 PATRIMONIA-INCUAPA (UE CONICET-UNICEN)

E-mail: griseldalemiez@hotmail.com

2 PATRIMONIA-INCUAPA (UE CONICET- UNICEN) Departamento de Arqueología - Universidad Nacional del Centro de la Provincia de Buenos Aires.

E-mail: mendere@soc.unicen.edu.ar 
historical reconstruction was made based on alternative sources, that is, journalistic, judicial, photographic, etc., supported and/or contracted with the oral memory of some of their protagonists. Finally, we wish to remember the role that documentary heritage plays in social memory and in democracies, for which we consider that it must be preserved and socialized. For this reason, it is a priority to have an adequate and updated regulatory framework to protect it.

Keywords: Documentary heritage; Private files; Legislation; Working History.

Sumario. 1. Introducción. 2. La protección legal del patrimonio documental. 3. El caso de la empresa Calera Avellaneda S.A. de la ciudad de Olavarría. 4. Discusión y conclusiones. 5. Agradecimientos. 6. Referencias bibliográficas.

Cómo citar: Lemiez, G.; Endere, M.L. (2020) Patrimonio documental, memorias e historia obrera. La reconstrucción del caso de Villa Carlos von Bernard, partido de Olavarría, Buenos Aires, Argentina, en Revista General de Información y Documentación 30 (2), 507-526.

\section{Introducción}

El patrimonio documental permite reconstruir el pasado a partir de los documentos que dan cuenta de eventos a los que se les atribuye significación social. En este sentido, se ha afirmado que se trata de una construcción social (Prats, 2004), que está asociada a la percepción del paso del tiempo y a la necesidad de retenerlo materialmente a través de documentos que fijan y registran acontecimientos que necesitan ser recordados (Dorado Santana y Hernández Galán, 2015:33). Este patrimonio constituye además la memoria registrada de los pueblos y una parte sustancial del patrimonio cultural tangible, ya que los documentos (cualquiera sea su soporte) nos informan sobre los aspectos más diversos de nuestro pasado (Iarritu y Endere, 2009).

En el marco de este trabajo se entiende por documento a un objeto con contenido informativo analógico o digital y al soporte en el que se consigne. Un documento constituye un bien mueble; su contenido pueden ser signos o códigos (por ejemplo, texto), imágenes (fijas o en movimiento) y sonidos susceptibles de ser copiados o migrados. El soporte, además, puede tener propiedades estéticas, culturales o técnicas de importancia, de modo que la relación entre el contenido y el soporte puede ser desde accesoria hasta esencial (ver UNESCO, 2015).

No obstante, los bienes bibliográficos y documentales son algo más que objetos de valor histórico y artístico, "representan la aportación singular al conocimiento universal que cada colectivo realiza al conjunto de su cultura”. Por ello sólo pueden comprenderse en el marco de las relaciones sociales e históricas en que fueron producidas. De modo que para reconocer los documentos como elementos importantes de la construcción de la memoria colectiva en el discurso disciplinario se requiere considerarlos como productos culturales que responden a determinados procesos históricos y sociales. Además, es necesario que el alcance de su protección no se oriente sólo a la custodia de los testimonios del pasado sino también a garantizar la continuidad en la conformación de los acervos, ya que ellos "no solo sólo aportan al conocimiento, sino que dan cuenta además del acontecer social e institucional del colectivo” (ver García, 1999:79). 
En este sentido se ha afirmado que el patrimonio documental "comprende aquellos documentos o grupos de documentos que contienen un valor significativo y duradero para una comunidad, una cultura, un país o para la humanidad en general" (UNESCO, 2015) y debe ser preservado en tanto es representativo de la memoria e identidad de los pueblos. En el caso particular que nos ocupa, es decir los archivos industriales, la documentación existente contiene un determinado valor histórico en tanto refleja la realidad económica, social y política de determinadas épocas y entornos. Es común observar que las personas consideren que la papelería habitual, como cartas y facturas, apenas tienen interés, dado que generalmente se trata de rígidos y estereotipados textos comerciales. Sin embargo, estos escritos del pasado, por repetitivos e impersonales que sean, nos ponen en contacto con las personas de otros contextos históricos, pudiéndose recuperar pequeñas historias que surgen del olvido. A menudo, como señala Astibia (2009: 26), "en las viejas misivas se escapa un comentario personal, una queja, un temor, una situación laboral difícil, una recomendación, una relación entre amigos, reflejos de la vida y sociedad de antaño".

En efecto, existe toda una serie de elementos que nos sirven para conocer un determinado momento histórico y constituyen un valioso aporte a la reconstrucción del pasado. Facturas, hojas de correspondencia, catálogos, anuncios, etiquetas, y otros documentos integran ese patrimonio que, además de la información textual, suele presentar una interesante información gráfica que aluden a la distribución de los productos, presencia de alguno de esos productos o de algún elemento que simboliza la actividad o el producto industrial (Ruiz de Azúa, 2013: 12). El uso de fuentes iconográficas para ubicar la localización y características de sitios industriales históricos es aún limitado como herramienta de la arqueología industrial. No obstante, la combinación del trabajo de campo con la evidencia gráfica, las descripciones tecnológicas y las direcciones geográficas y postales son útiles y necesarias para llevar a cabo el inventario del patrimonio industrial de una región. Estas representaciones gráficas son además, "la partida para todo rescate identitario del patrimonio industrial” a través de "toda forma de representación que refresque la memoria de un pasado cuyas imágenes se niegan a morir para la colectividad de un pueblo o región” (Morales, 2011: 126). La importancia de estos elementos radica en que son bienes culturales que se han forjado y a los que la comunidad reconoce y dota de un simbolismo particular, convirtiéndose en parte de su identidad.

Por otra parte, el patrimonio documental es uno de los tantos vestigios de la actividad industrial que ha permanecido conservado a lo largo del tiempo como testimonio histórico de una actividad técnica y de su impacto social y económico en el entorno, y algunas veces, lo única que queda de ella. Sin embargo, los archivos industriales se convierten en un patrimonio que se ha visto sometido a un deterioro acelerado, víctima de las diversas circunstancias y del abandono (González Pedraza, 2010), por lo que su situación es particularmente crítica.

Los archivos, además, constituyen medios de defensa jurídica para sus propietarios. En efecto, los documentos constituyen instrumentos de conocimiento que se utilizan como medios indispensables de la administración y sirven para 
promover acciones administrativas y legales que tienen consecuencias en los individuos, en las empresas y en la sociedad (González Pedraza, 2010).

Dentro del universo de patrimonio cultural, el patrimonio documental presenta sus problemáticas y particularidades para todo estudio que intente analizar e interpretar su contenido. En tal sentido, son objetos con características especiales que requieren tratamientos y análisis diferente al resto de los conjuntos que forman parte del patrimonio cultural. Son bienes culturales cuya apreciación social requiere de mediadores capaces de descifrar su significado en el contexto y el momento histórico en que surgieron y de "identificar su valor, carácter representativo y significación para una determinada comunidad” (Dorado Santana y Hernández Galán, 2015: 29).

En relación con lo anterior, quisiéramos destacar la importancia del análisis de los archivos empresariales industriales, dado que en ellos encontramos una fuente sumamente rica y poco explorada para la investigación histórica. Consideramos que los archivos de las fábricas, son un recurso inagotable para la historia social, económica e incluso política, del cual se pueden obtener diversidad de información. Si bien el creciente desarrollo en el campo de la historia de las empresas, está supeditado a las dificultades que presenta el acceso a los archivos de fábrica y esto, en parte, ha obstaculizado cuestiones relacionadas con el análisis de la trayectoria de las empresas, gracias a la incorporación de nuevas fuentes se han logrado reconstruir las condiciones de producción, los trabajadores, el papel de las redes sociales, etc. (Ceva, 2008:385).

Los archivos empresariales constituyen una parte importante del patrimonio documental de la industria y ofrecen datos que son indispensables para analizar cuestiones específicas relativa a los vínculos construidos entre las empresas, diferentes entidades (públicas, privadas y del tercer sector) y la sociedad en su conjunto. Por ello resulta de gran importancia el acceso a las fuentes empresariales y, sobre todo, la posibilidad de poder contrastar con otras fuentes, ya que brindan otro tipo de información y demuestran características específicas de determinadas relaciones sociales.

Creemos que todo lo que constituye el patrimonio documental de la industria en la ciudad de Olavarría, genera un aporte valioso para poder reconstruir y analizar la identidad de la ciudad, que se fue conformando y resignificando según los diversos contextos, siempre ligada a la actividad industrial cementera. Por tal motivo, en el siguiente trabajo nos proponemos, como objetivo, recuperar y reflexionar sobre el aporte que las fuentes consideradas como patrimonio documental, nos brindan para la reconstrucción y el análisis histórico. Tomaremos como caso de estudio la empresa Calera Avellaneda S.A., ubicada en el partido de Olavarría ${ }^{3}$, en el centro geográfico de la provincia de Buenos Aires, Argentina. La metodología empleada se centrará en el análisis de fuentes éditas e inéditas, escritas y orales, documentación histórica y fuentes legales.

3 En Argentina, la unidad territorial que corresponde a la entidad política de municipio se denomina partido y está comprendido por áreas urbanas y rurales. 


\section{La protección legal del patrimonio documental}

El primer paso para abordar la cuestión del marco legal aplicable al patrimonio documental en Argentina consiste en identificarlo como parte del patrimonio cultural. La norma de mayor jerarquía de nuestro sistema legal, la Constitución Nacional (C.N.), contempla al patrimonio cultural en su art. 41 en el que se establece que "las autoridades proveerán a la preservación del patrimonio natural y cultural” (...). Asimismo, se especifica que "corresponde a la Nación dictar las normas que contengan los presupuestos mínimos de protección, y a las provincias, las necesarias para complementarlas, sin que aquellas alteren las jurisdicciones locales". Ello significa que es el Estado Nacional quien debe dictar la "leyes de marco", las que deberán, a su vez, ser complementadas por las respectivas normas provinciales (Endere, 2000).

En materia de patrimonio cultural todavía no se ha sancionado una ley nacional de presupuestos mínimos, pese a que la cláusula constitucional del art. 41 fue incorporada en la reforma de 1994, es decir, que ya cuenta con varias décadas de vigencia. No obstante, existen normas nacionales que regulan distintos tipos de patrimonio (e.g. la Ley 12.665 de Patrimonio Histórico y Artístico, la Ley 25.743 de Patrimonio Arqueológico y Paleontológico, etc.), las cuales constituyen el marco regulatorio general, el cual no está desprovisto de complejidades y vacíos legales.

Cabe recordar que la Ley 12.665 de 1940 que protege a los monumentos, lugares y bienes históricos nacionales, en su versión original, contemplaba la declaración de utilidad pública de "documentos de propiedad de particulares" que se considerasen "de interés histórico o histórico-artístico a los efectos de la expropiación” (art. 3). Sin embargo, los documentos fueron excluidos en reformas posteriores de esta norma (ver Ley 27.103/15).

En 1999 se sancionó la Ley 25.197 de Régimen de Registro del Patrimonio Cultural cuyo objeto es la creación de un inventario y registro nacional de bienes culturales. En su art. 2 incluye en la categoría de bien cultural histórico-artístico a "los manuscritos raros e incunables, códices, libros, documentos y publicaciones de interés especial, sueltos o en colecciones", así como a "los documentos de archivos, incluidos colecciones de textos, mapas y otros materiales, cartográficos, fotografías, películas cinematográficas, videos, grabaciones sonoras y análogos”. Lamentablemente esta norma nunca fue reglamentada por lo que no es operativa en la práctica.

De modo que no existe en Argentina una ley integrada o general de protección del patrimonio documental que abarque tanto a documentos inéditos como a publicaciones. Si bien la Ley 11.723 de Propiedad Intelectual protege las obras éditas, al regular el depósito legal de publicaciones que quedan bajo la custodia de la Biblioteca Nacional, no hay una normativa que proteja los documentos inéditos, como pueden ser los manuscritos de valor histórico o biográfico. Existen dos leyes específicas en la materia, una que regula el funcionamiento de las bibliotecas populares (Ley 419 de 1870) y la otra que rige al Archivo General de la Nación (Ley 15.930 de 1961). Este Archivo tiene por finalidad "reunir, ordenar y conservar la 
documentación que la ley le confía, para difundir el conocimiento de las fuentes de la historia argentina” (art 1). Entre sus funciones están las de: a) Mantener y organizar la documentación pública y el acervo gráfico y sónico pertenecientes al Estado nacional (...), o la documentación privada que le fuera entregada para su custodia; b) Ordenar, clasificar y facilitar la consulta de sus colecciones; c) Inventariar, catalogar y divulgar los documentos y fondos documentales; d) Publicar repertorios y series documentales; e) Difundir por cualquier otro medio el conocimiento del material existente en el archivo; etc. (art. 2). ${ }^{4}$ Asimismo se establece que los archivos históricos oficiales de todo el país tendrán una organización uniforme para lo cual invita a las provinciales a adherir a esta ley (art. 10).

A los fines de esta norma se consideran "documentos históricos" (art. 16):

a) Los de cualquier naturaleza relacionados con asuntos públicos expedidos por autoridades civiles, militares o eclesiásticas (...), como así también sellos, libros y registros $\mathrm{y}$, en general, todos los que hayan pertenecido a oficinas públicas o auxiliares del Estado y tengan una antigüedad no menor de 30 años;

b) Los mapas, planos, cartas geográficas y marítimas con antigüedad de, por lo menos, 50 años;

c) Las cartas privadas, diarios, memorias, autobiografías, comunicaciones y otros actos particulares y utilizables para el conocimiento de la historia patria;

d) Los dibujos, pinturas y fotografías referentes a aspectos o personalidades del país;

e) Los impresos cuya conservación sea indispensable para el conocimiento de la historia Argentina, y

f) Los de procedencia extranjera relacionados con la Argentina o hechos de su historia (...).

Respecto de los documentos en manos de particulares el art. 6 establece que "Los archivos y libros de entidades con personería jurídica y de asociaciones civiles, cuando ocurra su disolución o extinción legal, serán destinados al Archivo General de la Nación o al archivo general de la provincia que corresponda, según el caso” una vez transcurridos 20 años. Para efectuar la consulta de los archivos y libros de aquéllas tendrán que haber pasado 50 años de la fecha de la disolución o extinción legal salvo expresa autorización de los interesados, siendo la Inspección General de Justicia u organismos con funciones análogas los encargados de velar por su cumplimiento. $^{5}$

La misma norma establece que los documentos de carácter histórico son de interés público y no podrán extraerse del territorio nacional, sin previa autorización

4 Conforme al Decreto 1131/2016 el Archivo General de la Nación deberá definir los documentos y expedientes digitalizados que deberán conservarse en soporte original debido a su valor histórico (art. 7).

5 En la provincia de Buenos Aires esa función recaería la Dirección Provincial de Personas Jurídicas. 
del Archivo General de la Nación (AGN) (art. 17). No obstante, no se prohíbe la tenencia de documentos históricos por parte de particulares, aunque la regula. En efecto, dichos documentos deben ser denunciados por sus poseedores al AGN o al archivo general provincial correspondiente (art. 19). Ello significa que los poseedores tienen el deber de individualización del documento, así como el de darle una adecuada conservación (ver art. 20); pueden optar por dejarlos en depósito en el AGN y además deben comunicar a dicho organismo cualquier cambio de titularidad sobre los mismos (art 21), estableciéndose sanciones para casos de incumplimiento (art. 26).

Más allá de las normas mencionadas, no existe un sistema nacional de archivos ni un órgano regulador o coordinador de la política archivística a nivel nacional (Swiderski, 2004: 47, 2015, ver también Bazán y Monsalvo, 2002, 2011). De modo que el panorama es bastante desolador, teniendo en cuenta que la mencionada ley de propiedad intelectual si bien de manera indirectamente ayuda a la protección del patrimonio bibliográfico de Argentina, no está orientada específicamente a su salvaguarda. Además, esa ley presenta "fallas y blancos legislativos", los que sumados a "los defectos de su aplicación", la tornan inadecuada para la protección de las obras publicadas. A su vez, no existen mecanismos efectivos para la protección de los documentos inéditos que "obligue a las instituciones o particulares a declarar su posesión” (Bazán y Monsalvo, 2011), tampoco existe una regulación general en materia de archivos que se encuentran en museos o en otros tipos de bibliotecas como las universitarias y especializadas. Se observa, además, una tendencia a la fragmentación y diversificación de las políticas de protección, acentuada por el surgimiento de instancias locales de gestión, dada las particularidades de nuestro sistema federal por el cual el patrimonio cultural es de dominio provincial (Iarritu y Endere, 2009).

En la provincia de Buenos Aires el organismo de aplicación en la materia es el Archivo Histórico de la Provincia "Ricardo Levene”, creado en 1925. En 1957 se lo autorizó a ejercer funciones de asesoramiento técnico a los archivos de las Municipalidades Provinciales (Decreto-Ley 21.040/57). En 2003, se actualizaron sus funciones, entre las que se encuentran, además de las usuales (i.e. acrecentar, preservar, difundir, custodiar, restaurar, organizar y actualizar el registro documental), las de supervisar y ejercer el control técnico de los archivos de los poderes públicos provinciales y proponer la celebración de convenios con organizaciones gubernamentales y no gubernamentales en materia de asistencia y colaboración técnica (Decreto 1.940/03).

Como puede observarse, estas normas, en general, tienen por objeto la preservación de documentos que revisten "interés histórico o patriótico" y casi exclusivamente vinculados con los archivos públicos (ver art. 3 Decreto-Ley 21.040/57).

Para completar el marco legal existente, cabe mencionar que, en 2013, se sancionó la Ley 26.899 que creó el sistema nacional de repositorios digitales institucionales de acceso abierto para los organismos e instituciones públicas que componen el Sistema Nacional de Ciencia, Tecnología e Innovación. Este sistema se aplica a: a) conjunto de documentos (artículos de revistas, trabajos técnico- 
científicos, tesis académicas, etc.), que sean resultado de actividades de investigación; b) datos primarios de investigación a través de repositorios digitales institucionales de acceso abierto o portales de sistemas nacionales de grandes instrumentos y bases de datos, c) políticas institucionales para su gestión y preservación a largo plazo.

Pese a que la protección en el territorio nacional es endeble, existen normas claras respecto de la protección de los documentos históricos en el ámbito internacional. En efecto, Argentina ha ratificado convenciones elaboradas por diferentes organismos internacionales que protegen al patrimonio documental ${ }^{6}$, en especial el primer protocolo de la Convención para la Protección de los Bienes Culturales en caso de Conflicto Armado (UNESCO, 1954), la Convención sobre Medios para Prohibir y Prevenir la Importación, Exportación y Transferencia Ilícita de Bienes Culturales (UNESCO, 1970); la Convención de UNIDROIT sobre los Bienes Culturales robados o exportados ilícitamente (UNIDROIT, 1995), además de la Convención de San Salvador sobre defensa del Patrimonio Arqueológico, Histórico y Artístico de las Naciones Americanas (OEA, 1976).

De todas ellas, las más significativas son las Convenciones de UNESCO de 1970 (ratificada por la Ley 19.943 de 1972) y de UNIDROIT de 1995 (ratificada por la Ley nacional 25.257 de 2000). En la primera convención se enumeran, entre las diferentes categorías de bien cultural a proteger, a "los manuscritos raros e incunables, libros, documentos y publicaciones antiguos de interés especial (histórico, artístico, científico, literario, etc.) sueltos o en colecciones; así como a los archivos, incluidos los fonográficos, fotográficos y cinematográficos” (ver art. 1 inc. h y j). Sin embargo, esta convención establece como requisito para que tales bienes culturales queden protegidos en los términos de la convención que ellos hayan sido "expresamente designados por cada Estado como de importancia para la arqueología, la prehistoria, la historia, la literatura, el arte o la ciencia”. De modo que se requiere un proceso previo de inventario por parte del Estado Parte.

El UNIDROIT (Instituto para la Unificación del Derecho Privado Internacional) en su Convención sobre la Restitución de Objetos Culturales Robados o Exportados Ilegalmente de 1995 reprodujo en el anexo el mismo listado de bienes culturales que la Convención de UNESCO de 1970, por lo que los documentos y archivos también están incluidos. A su vez, esta convención no exige que los bienes que se reclamen hayan sido previamente inventariados por el Estado, lo que constituye una condición beneficiosa para el Estado argentino. No obstante, esta Convención cuenta con menos ratificaciones que la de UNESCO, por lo que puede ser invocada ante un número menor de Estados Partes.

Las disposiciones de estas convenciones, sumadas a las que establece la Ley 15.930 brindan medios legales para proteger al patrimonio documental contra el tráfico ilícito de bienes culturales. Por otra parte, existen otros mecanismos legales para proteger el patrimonio documental en peligro. Uno de ellos es la acción de

$6 \quad$ No se mencionan aquí las convenciones relativas a derechos de autor, ya que su objetivo no es la protección del patrimonio documental sino los derechos de propiedad intelectual (ver Endere, 2007). 
amparo, prevista en el art. 43 de la C.N., ante acciones u omisiones de autoridades o particulares que sean violatorios del derecho al patrimonio cultural. El otro mecanismo es el de denuncia penal contra el delito de daños ejecutados en archivos, registros, bibliotecas o museos, que está contemplado en el art 184 inc. 5 del Código Penal (ver Vassallo y García, 2013).

\subsection{Iniciativas en el ámbito internacional}

Cabe destacarse además la existencia de diferentes iniciativas a nivel internacional para proteger el patrimonio documental. Así, en el marco del MERCOSUR, se adoptó en 1996 el Protocolo de Integración Cultural entre los gobiernos de Argentina, Brasil, Paraguay y Uruguay. Uno de sus objetivos fue el de promover entre los Estados Partes una relación directa entre archivos históricos, bibliotecas, museos (...) a fin de establecer acuerdos institucionales para la unificación de criterios relativos a la clasificación, catalogación y preservación que conduzcan a la creación de un registro del patrimonio histórico-cultural de la región (ver art. IV).

A su vez, la UNESCO creó en 1992 el Programa Memoria del Mundo con el objetivo de dar difusión al patrimonio documental mundial a fin de incrementar la conciencia y la protección de dicho patrimonio y lograr su accesibilidad universal y permanente (Edmondson, 2002). Este programa cuenta con la colaboración de la Federación Internacional de Asociaciones de Bibliotecarios y Bibliotecas (IFLA) y el Consejo Internacional de Archivos (CIA), quienes trabajan de manera conjunta en la preparación de Directrices para la Salvaguarda del Patrimonio Documental. El documento más reciente es la Recomendación Relativa a la preservación del patrimonio documental, comprendido el patrimonio digital y su acceso aprobada por UNESCO en 2015. ${ }^{7}$

Estos documentos promueven la adopción de normas por parte de los Estados miembros, así como de buenas prácticas de gestión documental a fin de garantizar la accesibilidad y la preservación de los documentos, a través de la observancia de principios básicos como la integridad, la autenticidad y la fiabilidad (ver Vairo Botta, 2017).

\section{El caso de la empresa Calera Avellaneda S.A. de la ciudad de Olavarría}

La empresa que tomamos como caso en este estudio, está situada en el paraje San Jacinto, en el área serrana del Partido de Olavarría y fue fundada por la Calera Avellaneda Sociedad Anónima en 1921, cuando se adquirieron las Canteras de San

\footnotetext{
Merecen destacarse como antecedentes la Recomendación sobre la Salvaguardia y la Conservación de las Imágenes en Movimiento (1980); la Recomendación sobre la promoción y el uso del plurilingüismo y el acceso universal al ciberespacio (2003); la Carta sobre la preservación del patrimonio digital (2003). Declaración Universal sobre los Archivos (UNESCO 2011); Declaración de Vancouver: La Memoria del Mundo en la era digital: digitalización y preservación (UNESCO/UBC 2012), etc. (ver Vairo Botta, 2017).
} 
Jacinto, en su tiempo, propiedad de los señores Serrano y Cía. (El Popular, 26 de mayo de 1929).

La cantera poseía yacimientos de arcilla, loess, cuarzo y 75 hectáreas de piedras calcáreas en compacta formación. Ante esa enorme cantidad de materia prima, y "la riqueza de la piedra", se inició la obra de organizar "una moderna fábrica de cemento Pórtland” (El Popular, Anuario de 1935:108). Las actividades de la empresa adquirente se habían iniciado con una pequeña fábrica de cal en el partido de Avellaneda (provincia de Buenos Aires); de esta ubicación inicial y de su rama de actividad surgió la denominación Social "Calera Avellaneda S.A.”, que luego habría de tomar otros rumbos y dimensiones (El Popular, 26 de mayo de 1929).

En sus inicios, la piedra provenía de las canteras, arrendadas primero, y adquiridas más adelante, junto a las cuales se trasladó la planta industrial. Una vez instalada en Olavarría, la cantera de la entonces precaria fábrica, se convirtió en un establecimiento de gran capacidad productiva. Pero no solo se concretó la producción de cal, sino que viendo las grandes posibilidades que ofrecía la piedra de ese paraje, instaló hornos para la producción de cemento Portland que tuvo su inicio en 1935 (García, 2004: 8). Desde su apertura, Calera Avellaneda S.A. constituyó una promesa para el futuro, por lo que se sucedieron las ampliaciones y modernizaciones de las fábricas de cemento y cal, consolidándose marcas ya tradicionales en el mercado argentino como cal "Hidrat" y "Cemento Avellaneda" (La Democracia, 1 de enero de 1930).

La gran expansión productiva, demandó la instalación permanente de los trabajadores, con la intención de que estos permanecieran cercanos a la fábrica. Desde la empresa se buscaba fijar la mano de obra, dada las características del proceso de producción, y fue la propia fábrica la que creó un mercado de trabajo, antes inexistente, mediante la construcción de viviendas para los obreros (Neiburg, 1988: 20). La ausencia de un mercado de trabajo, fue el motivo que impulsó a la empresa a tomar la iniciativa en 1938 de construir en un principio el denominado Pabellón para obreros solteros, que consistía en una serie de viviendas y que contaba, entre otras cosas, con una instalación frigorífica para la conservación de carne y demás productos alimenticios. Esta construcción permitía a quienes llegaban de zonas alejadas permanecer allí de forma gratuita y, por otro lado, la empresa se aseguraba de la permanencia de los empleados en la cercanía de su fuente de trabajo. Este sector destinado a alojar trabajadores sin familias contaba con cuarenta habitaciones, de una a cuatro plazas cada una, dos secciones de baño, cinco depósitos, dos cocinas, comedor y un salón de esparcimientos (García, 2004: 36).

La necesidad de incorporar más trabajadores al proceso productivo, en estrecha relación a la necesidad de aumentar el ritmo de producción, fue lo que llevó a la ampliación del lugar. De esta forma, la residencia transitoria para hombres solteros fue el inicio de la construcción de una villa obrera, un pequeño poblado que llegó a ser habitado por más de 700 personas, incluyendo hombres, mujeres y niños. La ampliación de la villa obrera coincide con la llegada a la Dirección de la empresa de Carlos von Bernard, en 1941. Se construyeron casas para obreros y sus familias, viviendas para jefes y residencia para “el patrón”, además del almacén de Ramos 
Generales y diferentes negocios (peluquería, carnicería, mercería, zapatería y verdulería). También se construyó el Club Social y Deportivo Calera Avellaneda, piletas de natación, canchas de tenis, fútbol, básquet, golf y bochas, una escuela, un jardín de infantes y una capilla.

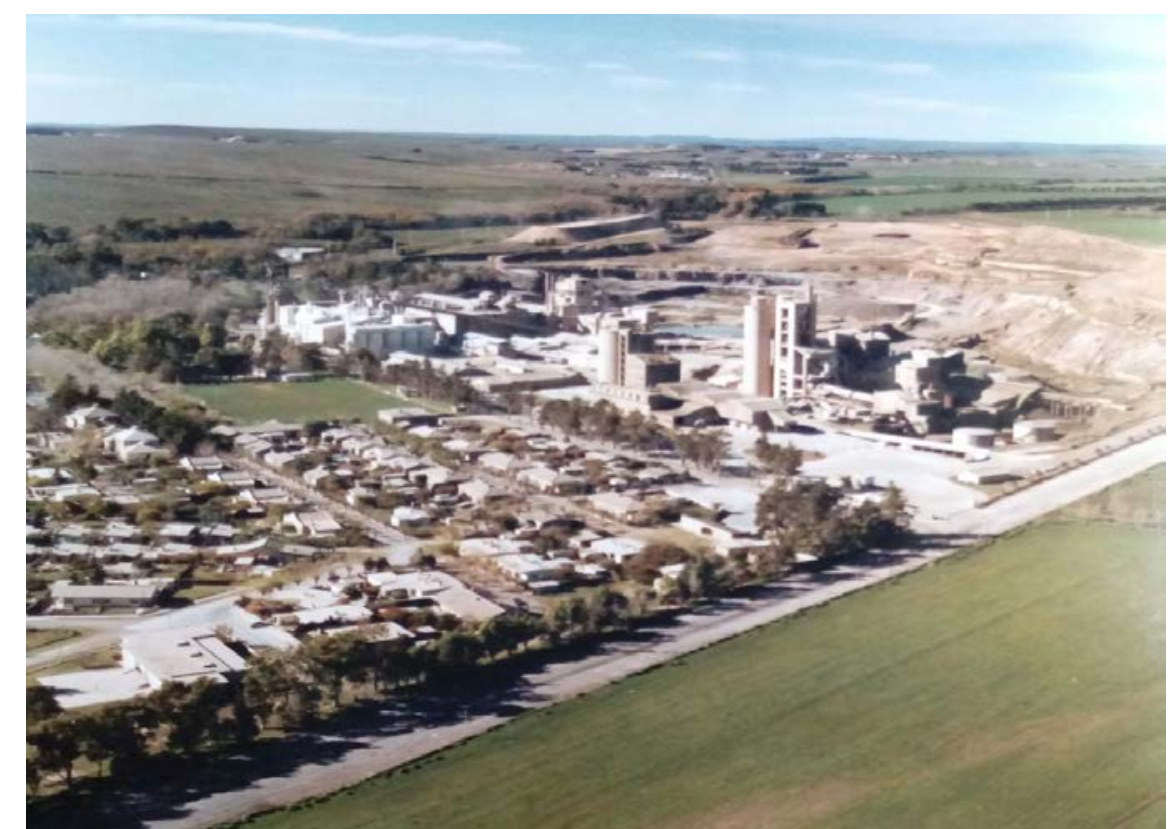

Figura 1. Foto satelital de la villa obrera Von Bernard, empresa Calera Avellaneda S.A., año 1975 (Fuente: Archivo Histórico Municipal de Olavarría).

La villa obrera pasó a denominarse "Villa Carlos von Bernard", estaba formada por unas 200 unidades de viviendas con 14.372 metro cuadrados cubiertos.$^{81}$ Las casas eran sólidas, altas y confortables. Eran construcciones de dos departamentos, compuesto cada uno por tres habitaciones, cocina, hall, baño y lavadero. Sus pisos eran graníticos en la cocina, en el comedor y en el baño, sus paredes de ladrillo de barro de primera y recubiertas con madera machimbrada. Tenían techo de chapa de fibrocemento, cocina a leña con serpentina y tanque intermediario que suministraba agua caliente para el baño y la cocina. En invierno, la cocina permanecía encendida día y noche con carbón mineral, que periódicamente proveía la fábrica a muy bajo precio. Contaban con instalaciones de servicios urbanos, tales como agua corriente, cloacas y luz eléctrica y también había recolección de residuos. ${ }^{9}$ La empresa también se hacía cargo del mantenimiento de las casas que integraban la villa, de modo que si había algo que reparar, los trabajadores lo comunicaban en la fábrica y de inmediato obtenían una orden de reparación.

8 La villa Von Bernard se encontraba muy próxima a la fábrica de cemento y estaba ubicada a unos $13 \mathrm{Km}$. de la ciudad de Olavarría.

9 Testimonio de un ex obrero de Calera Avellaneda y ex vecino de la villa obrera von Bernard, Alberto Soraisz, Olavarría, 06/02/2007. 
Las casas disponían de una amplia franja de terreno lateral que iba desde el frente hasta el fondo de la casa, además de una parcela posterior, donde la gente tenía su jardín, quinta y hasta algunas aves (García, 2004: 34). Los frentes de las casas estaban cercados con alambres tejidos, sostenidos por postes de cemento. Las calles tenían un cordón cuneta pero no estaban pavimentadas, salvo la calle principal que tenía un relleno de pequeñas piedras caliza que evitaban la formación de barro en los días de mucha lluvia (García, 2004: 34). Según los testimonios era un lugar tranquilo y seguro (custodiado por un sereno las 24 horas) y a ello debemos sumarle canteros con flores, las quintas, los parques y los juegos para niños.

Calera Avellaneda S.A. edificaba las viviendas destinadas a los obreros, pero no les daba la posibilidad de acceder a su propiedad, sino que las entregaba en forma de préstamo. De esta forma, la fuerza de trabajo era inmovilizada a través de la vivienda y tenían a su disposición electricistas, pintores y albañiles a los que podían acudir en caso de necesitarlos, pero las casas no podían ser refaccionadas ni ampliadas. ${ }^{10}$ En todos los casos, era un requisito imprescindible haber contraído previamente matrimonio para poder disponer de las mismas. Tanto el matrimonio como la conservación de la vivienda familiar, aparecen en este modelo industrial como los condicionantes externos de la disciplina en la fábrica (Babiano Mora, 1998:90).

Se podía identificar en el espacio que ocupaba la villa obrera tres zonas: en la primera de ellas se encontraban las casas destinadas a los trabajadores y sus familias, y el pabellón para trabajadores solteros, en la segunda habitaban los empleados jerárquicos, ingenieros y técnicos de la fábrica y, por último, un poco más alejada, se encontraba el chalet que ocupaba "el patrón" con su esposa. Dentro de la villa, también se encontraban parques y jardines con plantas frutales que era cuidados por personal contratado por la fábrica. La residencia del patrón se encontraba en la tercera zona, alejada de la casa de los trabajadores y en uno de los sectores más vistosos de la villa, rodeado por un inmenso parque muy próximo a la cancha de golf y tenis. Se observa al mirar el diseño arquitectónico de la villa obrera no estaba solo pensada para vigilar el espacio exterior, sino también para permitir un control interior articulado y detallado por parte de la empresa y, que reproducen en la distribución en el terreno y en los bienes materiales las diferencias de estratificación social y jerarquía laboral. Tal como indican algunos vecinos, cada uno sabía el lugar que le correspondía dentro de esta particular distribución espacial.

La empresa intervenía fuertemente en la villa obrera, sobre todo en la parte social, en una búsqueda constante de crear pautas y hábitos morales. El aislamiento se fundaba en la posibilidad de autosuficiencia que caracterizaba a la villa obrera, que reunía los espacios de vida y trabajo de los obreros, y en donde estos, encontraban todo lo necesario, para atender a las necesidades laborales, así como para atender a la salud, la educación y la recreación. Las relaciones personalizadas entre los trabajadores y la empresa, que dieron paso a la producción de relaciones paternalistas, tuvieron su manifestación más visible en la figura del "patrón" (Neiburg, 1988: 108). Dentro de este modelo de patronazgo se estructuraron y desestructuraron relaciones sociales personalizadas que dieron lugar a un sistema de

10 Testimonio de un ex vecino de la villa obrera von Bernard, Carlos Lobano, Olavarría, 05/10/2006. 
dominación, denominado sistema de fábrica con villa obrera (Neiburg, 1988) que se producía y reproducía constantemente. ${ }^{11}$ Carlos von Bernard fue el encargado de dar vida y forma a este particular sistema productivo. Durante su gestión, se formó un vínculo laboral con características y estilo propio, donde las relaciones sociales entre patrón y obreros, que se establecían en las esferas de la producción (fábrica) y la reproducción (villa obrera) de la fuerza de trabajo, funcionaron dentro de una normativa personalizada. Al morir von Bernard en 1973, sus herederos no supieron o no se interesaron en continuar la gestión de la villa obrera, y la situación empeoró con la venta de la empresa a capitales extranjeros. A comienzos de la década del ochenta, en una coyuntura de caída de la demanda de cemento y como resultado de un ajuste en los costos, la villa fue demolida y sus habitantes se disgregaron en otros centros urbanos del partido. De modo que la reconstrucción de la historia de la vida en villa obrera se apoya fundamentalmente en el rescate de su patrimonio documental.

\subsection{La documentación empresarial como patrimonio}

Los archivos de empresas tienen una serie de características que los hacen muy peculiares, convierten su estudio en una compleja tarea que tiene múltiples derivaciones y campos de estudio. Gran parte de esta complejidad deriva de la misma naturaleza de la empresa como sujeto histórico, económico y social, es decir, una especie de microcosmos en el que se producen múltiples interrelaciones. El archivo, a imagen y semejanza de su órgano productor adquiere la misma complejidad. La historia de la empresa explica el desarrollo de la misma a lo largo del tiempo y conocerla permite comprender su identidad. El primer paso consiste en acudir a las fuentes, adentrarse en el archivo de la empresa y recuperar la mayor cantidad y variedad de información posible. De este modo recobran importancia no sólo los documentos, textos, objetos y fotografías que fueron generadas por la propia empresa o de otras fuentes, sino además la memoria oral a través de los testimonios de los protagonistas (González Pedraza, 2010).

La construcción de una memoria colectiva de la minera en Olavarría ha sido hasta el momento el objeto de pocos estudios y esta falencia responde, en parte, a la ausencia de archivos históricos locales. En la preservación y conservación de las fuentes históricas locales, los archivos documentales cumplen un rol fundamental. Tanto el patrimonio tangible como el intangible que ha dejado el funcionamiento de una fábrica resulta importante y demanda un rescate patrimonial de carácter histórico y sociocultural por tratarse de una comunidad con características singulares (Ceva y Tuis, 2010:28). No obstante, el creciente desarrollo en el campo de la historia de las empresas está supeditado a las dificultades que presenta el

11 El patronazgo, como fenómeno general, puede definirse como un sistema político basado en relaciones personales entre desiguales, entre los líderes (patrones) y sus seguidores (clientes) Los clientes, ofrecen a sus a sus patrones su apoyo legal y su defensa, que se expresan en múltiples formas simbólicas. Por su parte, los patrones ofrecen a sus clientes protección contra la demanda de otros patrones, a modo de favores que van desde la hospitalidad hasta el empleo (Burke,1993: 90). 
acceso a los archivos de fábrica y esto, en parte, ha obstaculizado cuestiones relacionadas a la articulación entre la nueva historia del trabajo y el análisis de las trayectorias de las empresas familiares. Gracias a la incorporación de nuevas fuentes, se ha logrado reconstruir cuestiones relacionadas a las condiciones de producción, de trabajo, a las relaciones sociales, maritales, los roles familiares, así como a la endogamia profesional en las familias y el papel de la red de relaciones sociales (Ceva, 2008:385).

La imposibilidad de acceder al archivo empresarial de la empresa Calera Avellaneda S.A, nos llevó a buscar otras fuentes documentales que nos permitieron reconstruir algunos aspectos de la empresa. Así por ejemplo, la prensa local nos ha brindado información específica sobre las empresas cementeras de la ciudad de Olavarría y la posibilidad de contrastar y complementar dicha información con otros tipos de fuentes, como las orales.

En el Archivo Histórico Municipal de la ciudad de Olavarría, los ejemplares del Diario Tribuna, Diario La Democracia y Diario El Popular, si bien no se encuentran completas sus colecciones anuales, comparten buena parte de la información que se difundía sobre las empresas cementeras del partido. Algo similar ocurre con los Anuarios que estos diarios publicaban con la intención de conmemorar algún tipo de aniversario.

Una mención especial le atribuimos a un tipo de documentación que sin imaginarlo, se convirtió en la mayor fuente de información al momento de analizar las relaciones laborales construidas en las empresas cementeras de Olavarría entre 1940 y 1970: los Expedientes Judiciales. Estos son parte de causas correccionales del Juzgado de Paz de Olavarría, provincia de Buenos Aires que se encuentran en el Archivo Histórico Municipal de esa ciudad. La tardía creación del Tribunal de Trabajo derivó en que este tipo de causas formen parte de los expedientes del Fuero Penal y no del Fuero Laboral hasta 1970. Ante un Tribunal de trabajo ausente, las denuncias pasaron a formar parte de las causas penales ya que los trabajadores buscaron en el Estado la solución a sus conflictos laborales. En estos expedientes, se registran los actos procesales ordenados en forma cronológica y provistos de una carátula destinada a su individualización, que contiene los elementos más descriptivos de cada causa. Incluyen información del proceso sustanciado, donde se investigan los delitos reprimidos con pena no privativa de la libertad y aquellos sancionados con pena de prisión no mayor a tres años. Se trata mayormente de sumarios por lesiones leves, en donde se detalla el nombre de la víctima, del acusado, de los testigos, peritos y del Juez interviniente. Se incluyen informes médicos, de otros peritos (contables, calígrafos, etc.). Los hechos descritos en los expedientes judiciales dan muestra de conflictos y tensiones sociales y laborales que rara vez aparecen en la historia oficial de las villas obreras o llegan a las crónicas periodísticas.

Creemos que el cúmulo de interrogantes que se desprenden de este tipo de análisis nos acercan al mundo empresarial y del trabajo para poder introducirnos en los estudios de casos, como sustento esencial de una síntesis histórica integradora. Desde una perspectiva interdisciplinaria, se pueden adoptar herramientas de análisis para complejizar el entramado de relaciones interpersonales y definir 
pautas, como el perfil de empresarios u operarios, que se desprenden de los expedientes por medio de las variables tales como nacionalidad, sexo, niveles de instrucción, etc. (Bossio, 1989). Dichos documentos, permiten interpretar las estructuras y estrategias de las empresas, ya que las partes en conflicto brindan material probatorio para poder "reconstruir el universo de cada fábrica, sus técnicas productivas, sus políticas de reclutamiento de personal y hasta sus incapacidades de competitividad en un mundo cambiante" (Bossio, 1989: 352). Por otra parte, constituyen un disparador para reconstruir la historia oral a partir del análisis de historia de la fábrica, de sus relaciones laborales y de sus conflictos, entrevistando a los protagonistas cuyos datos surgen de los expedientes.

Los documentos visuales como las fotografías, también pueden ser utilizados como fuentes para la reconstrucción histórica. Cada vez más, encontramos en la historiografía un interés mayor por utilizar este material como fuente histórica en la reconstrucción de las historias locales. El siglo XXI se define como el siglo de las comunicaciones, pero perfectamente podría también definirse como el siglo de la «imagen» dada la trascendencia que esta ha alcanzado en la vida de las personas y las comunidades (Ferrer y Olivares, 2015:84).

En el estudio del caso que presentamos, fue de vital importancia la incorporación de las fotografías como documentos de análisis. Cabe reiterar que el espacio que ocupaba el sistema de fábrica con villa obrera de la empresa Calera Avellaneda S.A. actualmente no existe, ya que fue utilizado para ampliar el área de explotación en el marco de una estrategia empresarial de aumentar la producción de cemento. Sólo quedó en pie y en funcionamiento la fábrica de cemento. Es por ello que las fotografías satelitales de la fábrica y su villa obrera, junto al plano del lugar y los testimonios de quienes vivieron en ese sitio, nos permitió reconstruir y conocer cada uno de los espacios que integraban este modelo empresarial.

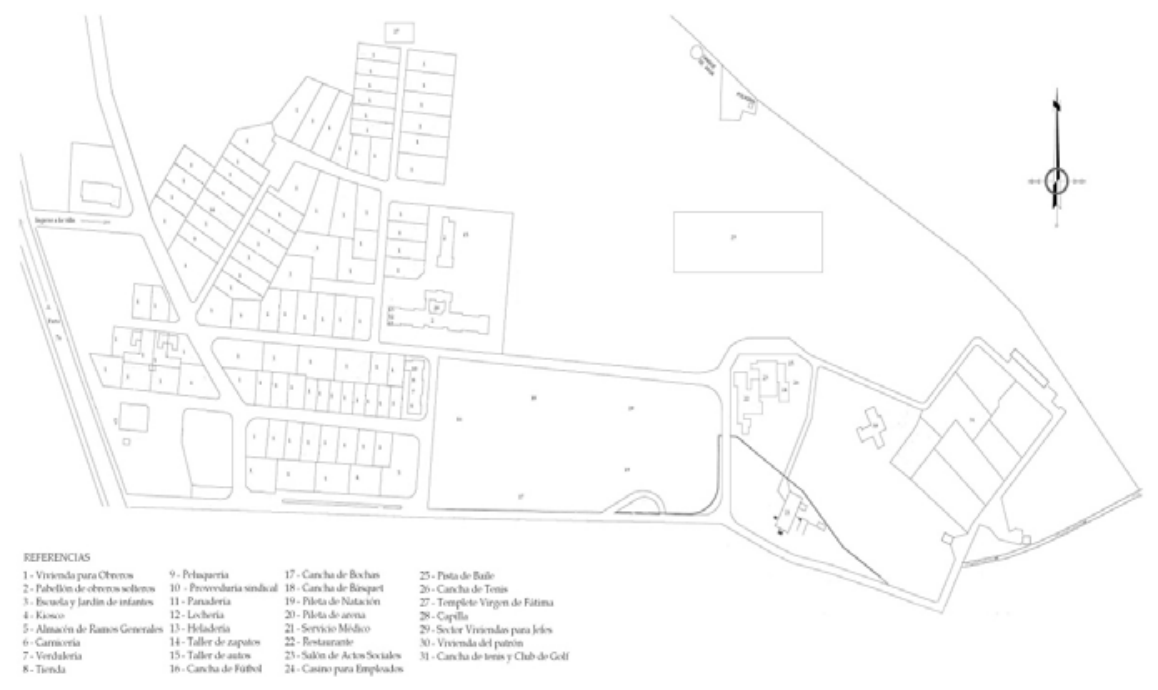

Figura 2. Plano con la distribución espacial de la villa obrera Von Bernard

(Fuente: Autoras) 
La utilización de las fotografías también sirvió para analizar lo cambios producidos en los espacios durante el periodo estudiado en relación a la reconfiguración de la actividad económica, es decir las modificaciones aplicadas al proceso de producción de cemento, vinculadas a las ventas según los diferentes contextos.

Por otra parte, consideramos que fue muy valioso para nuestro estudio poder acceder a las voces de los trabajadores, es decir a los testimonios de quienes fueron los principales actores en la historia de las empresas. La realización de diversas entrevistas, nos permitió acercarnos a un fenómeno tan complejo y sensible como es el mundo de las representaciones, que para el caso de Calera Avellaneda se relacionan entre otras cosas con la figura del patrón, las relaciones laborales, la vida en la villa obrera, la integración al orden productivo y la formación de los trabajadores como obreros del cemento y la propia identidad como habitantes de la Villa von Bernard.

\section{Discusión y conclusiones}

Como se afirmó previamente el patrimonio documental es una construcción sociocultural a partir del cual se construye y se reconstruye permanentemente la memoria colectiva y la identidad (Dorado Santana y Hernández Galán, 2015). Se trata de un proceso dinámico, ya que "es posible que el carácter significativo de este patrimonio solamente se evidencie con el paso del tiempo". Es por ello que las medidas destinadas a su preservación y protección "deberían guiarse por la legislación internacional y las recomendaciones, directrices, mejores prácticas y normas establecidas o avaladas por las instituciones encargadas de la memoria" (UNESCO, 2015).

En relación a los archivos privados y su protección legal en Argentina, consideramos que existe un vacío legal, particularmente en relación a los archivos de las empresas, de modo que resulta difícil encontrar la manera de conservarlos. Los documentos de particulares ocupan un lugar muy marginal tanto en la normativa como en los fondos documentales que poseen los propios archivos, a menos que formen parte de colecciones particulares, adquiridas por dichos organismos por tratarse de personalidades encumbradas de la literatura o el arte, etc. Esto genera la necesidad, y a la vez constituye un desafío, de poder contar con una normativa actualizada que se ocupe de todo el patrimonio documental, cualquiera sea su formato, y que permita salvaguardar la documentación, tanto oficial como privada.

La idea que subyace en muchas de las normas de patrimonio documental vigentes en nuestro país, está inspirada en una noción de patrimonio que ha quedado perimida. Es decir, aquella que consideraba solo importante la documentación vinculada con la historia oficial y con ciertos eventos que se quieren rememorar por ser de interés para la Nación. En general, las normas mencionadas tienen por objetivo la preservación de documentos que revisten 
“interés histórico o patriótico" principalmente vinculados con los archivos de carácter públicos (Swiderski, 2015).

Sin embargo, el cambio en la mirada y en la comprensión de la historia, caracterizado por un marcado interés en lo social, hace que recobren importancia nuevos documentos, que actualmente no están protegidos por estas normas. El acercamiento de la historia a las otras ciencias sociales ha llevado a establecer "marcas de ruptura y actualización de la disciplina histórica, que definen en la actualidad una nueva visión del papel social de la historia, del documento y de su manejo metodológico para la construcción de los estudios históricos” (Suárez Pinzón, 2012).

Respecto de los archivos locales observamos que prevalece el descuido y que se caracterizan por su poca sistematicidad (Iarritu y Endere, 2015). Centrándonos específicamente en los archivos empresariales, más precisamente en el caso particular de Calera Avellaneda S.A., vemos que tal como ocurre con la mayoría de este tipo de archivos, resulta prácticamente imposible acceder a dicha documentación. Esa particularidad, fue justamente lo que nos motivó a buscar otras fuentes que nos brindaran información y poder contrastarlas a fin de reconstruir algunos aspectos de las relaciones sociales y laborales que prevalecían en la empresa. Esto también nos motiva a reflexionar sobre el valor de las fuentes, como también sobre la importancia de identificar, sistematizar y conservar las fotografías que puedan colectarse. Deseamos destacar, además, la urgencia por preservar las fuentes aún existentes, tanto las documentales como las orales, dada la necesidad de concretar un trabajo sistemático de registro y de guarda de los testimonios. Todas estas actividades de recuperación, valoración y sistematización de documentos vinculados al patrimonio industrial minero, forman parte una agenda pendiente de investigación.

En ese marco, las fuentes orales cumplen un rol central para la investigación de la historia de las empresas ya que permiten contrastar las fuentes escritas en el proceso de reconstrucción histórica. Cuando nos referimos a las fuentes de empresas no se trata solo de documentos impresos o de archivos empresariales, sino también a otros elementos que constituyen un registro importante al momento de reedificar su trayectoria. Se trata de una memoria que no es solo material (y documentada) sino inmaterial y se aloja en la mente de los protagonistas. Su recuperación consiste en darle voz a aquellos actores que parecían no formar parte de historia, por no haber dejado expresado su testimonio de forma escrita y poder recuperar la riqueza histórica, acercándonos a la verdadera experiencia de los sujetos (Portelli, 1995).

Respecto a la utilización de las fuentes judiciales en la investigación histórica, consideramos que por medio de la información que nos brindan los expedientes judiciales podemos recuperar imágenes de época que permiten recrear situaciones de una sociedad que es dinámica y en transición. Los expedientes dan cuenta de procesos de interrelación que atraviesan a distintos sectores sociales y los relaciona en la reconstrucción de los procesos históricos. Permiten contrastar la imagen de la vida ideal en las villas obreras reproducida en el discurso oficial con las situaciones reales de disrupción y conflicto. Es, precisamente en el carácter discursivo de los 
testimonios de las partes involucradas en el conflicto, donde se puede rescatar "un microcosmo constituido por interacciones sociales permanentes y cambiantes, donde los testigos aparecen como parte de un proceso discursivo que puede ser estratégico" (Farge, 1989:10).

A través de la utilización de estas singulares fuentes, podemos acceder a la reconstrucción de algunos aspectos vinculados a las estrategias empresariales y a las relaciones laborales desplegadas en la industria del cemento, en un determinado momento histórico. Al contrastarlas con el resto de las fuentes mencionadas, nos permiten la reconstrucción de los conflictos laborales, las causas y formas que adoptaron esos conflictos y los modos de disciplinamiento, aplicados dentro y fuera de la empresa, cuestión que es clave en estos modelos empresariales considerados como sistemas de fábrica con villa obrera.

En suma, la reconstrucción histórica de la Villa Carlos von Bernard constituyó una tarea detectivesca donde debimos apelar a recuperar la "escena del crimen" con evidencias fragmentadas debido a la imposibilidad de acceder a una parte importante del registro documental. No obstante, la búsqueda de fuentes alternativas y diversas nos ha permitido recuperar la memoria espacial y reconstruir no sólo hitos importantes de la historia de la fábrica y la villa obrera, sino además aproximarnos a la comprensión de las interacciones sociales que se dieron en ella a lo largo de sus años de existencia.

Finalmente, no queremos dejar de recordar, como investigadoras sociales interesadas en el patrimonio cultural, la deuda pendiente en nuestro país respecto de la protección legal, la gestión y la conservación del patrimonio documental. Asimismo, señalar que más allá del interés propio de los investigadores, la preservación de los archivos en general, cumple un rol importante en nuestras democracias vinculado con el derecho de los ciudadanos de acceder a ellos y las políticas de accesibilidad a la información.

\section{Agradecimientos}

Este trabajo fue realizado en el marco del programa Interdisciplinario de Estudios del Patrimonio (PATRIMONIA), del Instituto de Investigaciones Arqueológicas y Paleontológicas del Cuaternario Pampeano (INCUAPA-UE CONICET), con financiamiento proveniente de los subsidios dirigidos por la Dra. María Luz Endere: PIP CONICET 1122015 - 0100106 CO "Estudio de las significaciones sociales del patrimonio cultural del partido de Olavarría, provincia de Buenos Aires. Propuesta metodológica para su visibilización y salvaguarda” y PICT ANPCyT 0551/2106 "Investigación, Gestión y Significación Social del Patrimonio Cultural en el Centro de Buenos Aires y Centro-Este de San Luis”. 


\section{Referencias bibliográficas}

Astibia Aierra, H. (2009). Paisajes de papel y patrimonio de la Era industrial vasconavarra. Madrid, Ediciones Dédalo.

Bazán: C. B., Monsalvo, P. E. (2011). Legislación sobre preservación del patrimonio documental y bibliográfico argentino. Disponible en: http://www.mundoarchivistico .com/?menu=articulos\&accion=ver\&id=325 [fecha de Consulta: 9/3/2020].

Babiano Mora, J. (1998). Paternalismo industrial y disciplina fabril en España (19381958). España: Concejo Económico y Social.

Bazán, C. y Monsalvo, P. (2002). Legislación sobre preservación del patrimonio documental y bibliográfico argentino. Departamento de Documentación - Facultad de Humanidades Universidad Nacional de Mar del Plata. Disponible en: www.bibnal.edu.ar/protopais/ mat/cat5.htm. Accedido el 9/3/2020.

Burke, P. (2003). Formas de Hacer la Historia, Madrid: Alianza.

Ceva, M. (2008). Familias obreras en la argentina de entreguerras. Un enfoque desde los archivos de empresa. Instituto de Estudios Históricos Sociales, Facultad de Ciencias Humanas, Universidad Nacional del Centro, Tandil, número 23.

Ceva, M. y Tuis, C. (2010). El Patrimonio Cultural en el Parque Industrial Algoselán Flandria. Revista Ciencia, 5, (20).

Del Valle Ferrer, R del. y Del Valle Olivares, C. (2015). La fotografía como fuente histórica en la construcción de las historias locales. Culturas (8), 81-96. https://doi.org/10.14409/culturas.v0i8.4779 .

Dorado Santana, Y. y Hernández Galán, I. (2015). Patrimonio documental, memoria e identidad: una mirada desde las Ciencias de la Información. Ciencias de la Información, 46(2), 29-34. [fecha de Consulta: 8 de Abril de 2020]. Disponible en: https://www.redalyc.org/articulo.oa?id=1814/181441052006

Edmondson, R. (2002). Memoria del Mundo: Directrices para salvaguardia del patrimonio del documental (CII-95/WS-11. Rev.). Disponible en http://unesdoc.unesco.org/ images/0012/001256/125637s.pdf [fecha de Consulta: 10/3/2020].

Endere, M. (2000). Arqueología y Legislación en Argentina. Cómo proteger el patrimonio arqueológico. Serie Monográfica INCUAPA, 1. Dpto. de Publicaciones UNICEN, Tandil.

Endere, M. (2007). Documento sobre la legislación nacional argentina y su relación con las convenciones establecidas por UNESCO dentro del Sector Cultural y Patrimonio Mundial. En: Legislaciones en el MERCOSUR relativas a las Convenciones de Cultura aprobadas por la UNESCO. Estudio de la situación actual en Argentina, Brasil, Paraguay y Uruguay, 7-42, editado por UNESCO, Sector Cultural y Patrimonio Mundial y Oficina Regional de Ciencia para América Latina y El Caribe, Montevideo.

Farge, A. (1989) La atracción del archivo. Valencia: Ediciones Alfons El Magnanim.

García, A. (1999). Los bienes bibliográficos y documentales: un acercamiento a su problemática. Investigación Bibliotecológica. 13 (26). Enero/junio.

García, M. (1998). La villa von Bernard. Entre violetas, aromos y recuerdos. Olavarría: Edición del autor.

González Pedraza, J.A (2010). El patrimonio industrial, el legado material de la historia económica, Areas, 29, 103-111.

www.bn.gov.ar/resources/conferences/pdfs/31/12-Vairo,\%20Daniela-\%20ponencia.pdf [fecha de Consulta: 18/4/2020]. 
Iarritu, N. y Endere, M. (2009). Patrimonio Documental en Azul, Olavarría y Tandil. En: Patrimonio, Ciencia y Comunidad. Su abordaje en los Partidos de Azul, Tandil y Olavarría, editado por M. Endere y J. Prado. Cap. 15, 303-313. UNCPBA, Olavarría.

Lobelle, G. (2012). Las políticas públicas de conservación y difusión del patrimonio documental. Necesidad de evaluación del impacto: el caso de la Oficina del Historiador de La Habana. (Tesis de Maestría). La Habana: Universidad de La Habana.

Morales Moreno, H. (2011). Breve historia de la publicidad industrial en México. La provincia industrial de Puebla entre el antiguo régimen y la revolución: 1880-1920 (rescate de patrimonio industrial intangible). México Revista Labor \& Engenho.

Neiburg, F. (1988). Fábrica y Villa Obrera: historia social y antropología de los obreros del cemento. Buenos Aires: CEAL.

Portelli, A. (1995). L'interpretazione dalle fonti orali. En Temas de Historia oral. Primer encuentro nacional de Historia Oral. Municipalidad de la ciudad de Buenos Aires.

Prats, L. (2004). El patrimonio como construcción social. En: Antropología y Patrimonio. Barcelona: Ariel.

Ruiz de Azúa, J. (2013). Trenes de papel. Madrid: OARSO.

Sierra Álvarez, J. (1990). El obrero soñado. Ensayo sobre el paternalismo industrial (Asturias, 1860-1917). Madrid: Siglo XXI.

Suárez Pinzón, I. (2012). Historia y archivística: memorias del poder. Revista Cambios y Permanencias, 3. Bucaramanga, 137-165

Swiderski, G. (2004). Legislación sobre el Patrimonio Documental y sobre el acceso a la información pública en la Argentina. Antropología de la Cultura y el Patrimonio. Diversidad y Desigualdad en los procesos culturales contemporáneos, editado por Mónica B. Rotman, 27-52. Córdoba, Ferreyra Editor

Swiderski, G. (2015). Las huellas de Mnemosyne. La construcción del patrimonio documental en la Argentina. Ciudad Autónoma de Buenos Aires: Biblos

Tanodi, B., Rapela, M. y Vasallo, J. (2005). Patrimonio Documental y Bibliográfico. Regulación Jurídica en la Argentina. Archivo General e Histórico, Córdoba: Universidad Nacional de Córdoba.

UNESCO (2015). Recomendación relativa a la preservación del patrimonio documental, comprendido el patrimonio digital, y el acceso al mismo. Aprobada por la Conferencia General de la UNESCO en su 38 ${ }^{a}$ reunión, París, 17 de noviembre 2015. Disponible en http://portal.unesco.org/es/ev.php-

URL_ID=49358\&URL_DO=DO_TOPIC\&URL_SECTION=201.html [fecha de Consulta: 19/04/2020].

Vairo Botta, D. (2017). Panorama general del patrimonio bibliográfico-documental en el MERCOSUR. Una mirada desde Uruguay. En Jornada El patrimonio bibliográfico en América Latina y el Caribe: desafíos y perspectivas. 27 y 28 de septiembre de 2017, Buenos Aires-Argentina.

Vassallo, J. y García, N. (2013). Derecho y Patrimonio documental en Argentina: la protección jurídica a través de la acción de amparo y la denuncia penal. Revista Documentación 32: 20-26. 